\title{
Does Patient Assessment of the Quality of the Primary Care They Receive Predict Subsequent Outcomes? An Oklahoma Physicians Resource/Research Network (OKPRN) Study
}

\author{
James W. Mold, MD, MPH, Frank Lawler, MD, MSPH, Kyle J. Schauf, MD, and \\ Cheryl B. Aspy, PhD
}

Introduction: We analyzed data from a cohort of 782 older patients assembled in 1999 to 2000 to determine whether baseline patient assessments of the quality of the primary care services they had received, measured using the Components of Primary Care Index (CPCI), were associated with subsequent changes in health-related quality of life (HRQOL) and/or survival.

Methods: Longitudinal growth curve models were used to analyze changes in Quality of Well-Being (QWB-SA) scores over an average (S.D.) of 2.07 (1.07) years. Cox proportional hazards models were used to identify variables associated with mortality over an average of 8.26 years (6460 person-years). To reduce confounding by severity of illness, subjects were stratified into disabled, nondisabled high utilizers of primary care, and nondisabled low utilizers. Within subgroups, we controlled for number of chronic illnesses and scores on the General Health subscale of the Medical Outcomes Study Short Form-36 (SF-36). We also controlled for baseline age, sex, marital status, income, body mass index, educational attainment, duration of the relationship with current primary care physician (PCP), and number of visits to the PCP in the year before entrollment. Analyses took into account clustering of patients within $P C P$.

Results: Neither total CPCI nor any CPCI subscale score was associated with QWB-SA change over time. Higher ratings of Coordination of Care were associated with reduced survival in the disabled and nondisabled high utilizer subgroups $(P=.007)$.

Conclusions: Assuming that effective primary care results in better HRQOL and longer survival and that the CPCI captures important primary care attributes, older patients' level of satisfaction with the quality of their primary care may not be a good surrogate measure of effectiveness. ( $\mathrm{J}$ Am Board Fam Med 2011;24:511-523.)

Keywords: Aged, Practice-based Research, Primary Care

Patients are a potential source of information about the quality of the primary care services they receive, and several instruments have been developed to

This article was externally peer reviewed.

Submitted 21 December 2010; revised 28 March 2011; accepted 13 April 2011.

From University of Oklahoma Health Sciences Center, Department of Family and Preventive Medicine, Oklahoma City, Oklahoma (JWM, FL, CBA); and Great Plains Family Medicine Residency (KJS).

Funding: Presbyterian Health Foundation and the University of Oklahoma Department of Family and Preventive Medicine.

Conflict of interest: none declared.

Corresponding author: James W. Mold, MD, University of Oklahoma Health Sciences Center, Department of Family and Preventive Medicine, 900 NE 10th St, Oklahoma City, OK 73104 (E-mail: james-mold@ouhsc.edu). obtain this information from them. ${ }^{1-3}$ One of these, the Components of Primary Care Index (CPCI), was developed by Flocke for use in the Direct Observation of Primary Care study. ${ }^{4}$ The CPCI is a reliable and valid measure of the quality of primary care services as perceived by patients. ${ }^{1}$ Based on the 1994 definition of primary care proposed by the Institute of Medicine in $1994,{ }^{5}$ it produces 8 subscale scores: Comprehensiveness, Accumulated Knowledge, Coordination, Preference for Regular Primary Care Physician (PCP), Interpersonal Communication, Advocacy, Family Context, and Community Context), and an estimated proportion of primary care visits made to the patient's usual PCP. The psychometric properties 
of the CPCI have been found to be similar in older as compared with younger patient populations (based on our unpublished analyses).

Two of the most important goals of health care are to prevent premature death and to preserve or improve health-related quality of life (HRQoL). The availability of primary health care services is a predictor of a variety of positive health outcomes across countries and across states within the United States. ${ }^{3,6-8}$ On the assumption that health care can be improved further through market forces, many recent efforts to control the costs of health care have included attempts to strengthen the ability of patients to choose their health care providers based on their assessments of quality. ${ }^{9,10}$

The primary purpose of this study was to determine whether patient assessments of the quality of their primary care, measured by CPCI subscale scores, were associated with better subsequent HRQoL and/or improved survival, that is, whether patients can accurately assess the effectiveness of the care they receive. The study was conducted in a cohort of older patients assembled for this purpose in 1999 and followed to March 31, 2010.

\section{Methods \\ Study Data}

The data used in this study were obtained from the Oklahoma Longitudinal Assessment of the Health Outcomes of Mature Adults (OKLAHOMA) Studies data set. Previous publications have described the methodology used to obtain this data in somewhat greater detail ${ }^{11,12}$ The study was reviewed and approved by the Institutional Review Board of the University of Oklahoma Health Sciences Center, and all subjects consented to participate, first by phone and then by signing a written consent form. Between January 1, 1999, and December 31, 2000, 23 family physician members of the Oklahoma Physicians Resource/Research Network (OKPRN) created, from their billing records, lists of patients 65 years of age and older seen by them within the prior 18 months. Patients were then excluded if they had switched physicians, died, were in nursing homes, or were thought by this PCP to be too confused to sign consent. Eligible patients received a letter from their physician inviting them to participate. Two weeks later, the project coordinator followed up with these patients by telephone. Those who agreed to participate were asked to complete a questionnaire sent to them 2 weeks before their enrollment visit.

The questionnaire included questions about demographic information, health habits, symptoms, medical conditions, activities of daily living skills (ADL; 14-point scale), instrumental activities of daily living (IADL; 14-point scale), the Medical Outcomes Study Short Form-36 (SF-36), selfrated health (5-point Likert and 100 point rating scales), and the Quality of Well-Being Self-administered Scale (QWB-SA). Participants were also asked about the length of their relationship with their current $\mathrm{PCP}$ and they were asked to estimate the number of visits to the PCP, other primary care providers, subspecialists, and emergency rooms and number of hospitalizations during the past year.

The questionnaure also included the CPCI instrument, which is composed of 43 questions from which one can calculate eight subscale scores. The number ofquestions used to calculate each subscale score ranged from 2 to 9. Each question was scored from 1 (Strongly Disagree) to 6 (Strongly Agree). Scores were averaged across questions yielding subscale scores of from 0 to 6 . A total score was calculated by summing across the eight subscale scores. The assumption was that these individual subscales, when summed, reflected an individual's overall perception of their primary care. Two questions were used to estimate the proportion of primary care visits made to the patient's usual PCP.

Two research nurses enrolled participants at their family physicians' offices at times scheduled specifically for this purpose. The nurses reviewed the study protocol, obtained informed consent, and checked the questionnaire for completeness. Each year on the anniversary of their initial enrollment, participants were invited to re-enroll. Those who agreed completed a follow-up questionnaire and were re-consented and briefly examined again by a research nurse. Numbers of participants enrolled in years 1 to 4 were 848, 597, 401, and 319, respectively.

Participant deaths were determined at the end of the 5-year study, using information provided by their designated contacts and primary care physicians and from the Social Security Death Index (http:// ssdi.rootsweb.ancestry.com/). Subsequently, deaths have been tracked using the Social Security Death Index.

Participants who changed primary care physicians during the original 4-year study were excluded from these analyses. We also excluded those 
for whom we could not calculate ADL or IADL scores because these scores were used to control for severity of illness (see below). If a participant did not answer the minimum number of items on a particular CPCI subscale, the score for that subscale was not calculated as per the scoring protocol developed by Flocke (Flocke, personal communication, 2008).

\section{Controlling for Severity of Illness}

To reduce the expected impact of severity of illness on potential associations between CPCI scores and outcomes, we used two strategies. First, we categorized participants a priori into clinically recognizable subgroups, based on baseline ADL/IADL composite score $<27 / 28$ (disabled subgroup) and, for the rest, number of PCP visits in the year before enrollment $(>4=$ high utilizers; $\leq 4=$ low utilizers). We then created a morbidity index by ascribing one point to the presence of each of the following chronic illnesses reported by participants at baseline and summing them: depression, diabetes mellitus, stroke, liver disease, Parkinson disease, autoimmune disease, lung disease, heart disease, or cancer. In addition, we controlled for patients' baseline General Health subscale score on the SF36. Because of the wide range of possible numbers of physician visits within the disabled and high utilizer groups, we controlled for numbers of physician visits during the year before enrollment as well.

\section{Health-Related Quality of Life}

Descriptive statistics were calculated for baseline variables for the entire cohort and for each of the three severity of illness subgroups. A correlation matrix was constructed for independent variables and QWB-SA scores. Linear regression models were then created within each severity subgroup to further evaluate baseline variables associated with baseline QWB-SA scores. Linear regression was also used to evaluate associations between PCP and baseline QWB-SA scores. Hierarchical (repeated measures within participants within PCPs) longitudinal growth curve analyses were performed within each severity subgroup, with QWB-SA scores in years 2 through 4 regressed on promising independent variables found in the linear regression models. This analysis method examines associations between independent variables and change in the dependent variable over time. In SAS, this proce- dure is called "PROC MIXED." Variables were removed from the models if they added little and were clinically unimportant. We then added each CPCI subscale score to each of the models to assess their independent impact on change in QWB-SA scores over time.

\section{Mortality}

Chi square and independent $t$ tests were used to analyze bivariate associations between baseline variables and death. Logistic regression models were created within each severity subgroup to further evaluate associations between baseline variables and mortality (in SAS, PROC GENMOD). Logistic regression was also used to assess strength of association between PCP and mortality. Hierarchical (participants within PCPs) Cox proportional hazards models (in SAS, PROQ PHREG) were then created for the entire cohort and within each subgroup by considering promising independent predictors of mortality and then removing variables with little or no contribution to the models and no clinical relevance. Individual CPCI subscale scores were then entered into these models.

Statistical Software and Adjustments for Skewing of CPCI Scores and for Multiple Analyses

All analyses were performed using SAS 9.1, version 5.1.2600. The degree of skewness for the total CPCI scores was -0.37 , with subscale skewness ranging from -0.59 for Family to -1.00 for Coordination and Preference for Regular Doctor. Because the CPCI total and subscale scores were skewed to the left, in addition to the standard analyses, we used an exponential transformation (exp $[\mathrm{x}])$ to achieve a more normal distribution. After exp transformation, the distribution of scores approached a normal distribution.

Because of multiple comparisons (total CPCI, 8 subscales, and proportion of visits to usual PCP; 3 severity of illness strata), we chose to consider associations with $P$ values less than 0.01 to be statistically significant.

\section{Results}

\section{Study Population}

Eight hundred fifty-four individuals completed the initial questionnaire. Sixty-six participants who changed PCPs during the 4 years of the study were excluded, as were 6 participants who answered 
Table 1. Characteristics of the Study Population and Comparison of Those Still Alive With Those Who Died

\begin{tabular}{|c|c|c|c|c|}
\hline Characteristics & All & Alive & Dead & $P$ Value \\
\hline Age category & 782 & & & \\
\hline 65 to 74 & 41 & $3(7 \%)$ & $38(93 \%)$ & \\
\hline 75 to 84 & 472 & $340(72 \%)$ & $132(28 \%)$ & \\
\hline $85+$ & 269 & $176(65 \%)$ & $93(35 \%)$ & 1 \\
\hline \multicolumn{5}{|l|}{ Sex } \\
\hline Male & 338 & $212(62 \%)$ & $126(37 \%)$ & \\
\hline Female & 444 & $307(69 \%)$ & $137(31 \%)$ & 0.06 \\
\hline \multicolumn{5}{|l|}{ Race } \\
\hline White & 668 & $446(67 \%)$ & & \\
\hline Non-white & 114 & $73(64 \%)$ & & 0.57 \\
\hline \multicolumn{5}{|l|}{ Marital status } \\
\hline Married & 272 & $152(56 \%)$ & & \\
\hline Other & 504 & $364(72 \%)$ & & 0.0001 \\
\hline \multicolumn{5}{|l|}{ Income } \\
\hline$<\$ 15,000 / \mathrm{yr}$ & 141 & & & $>$ \\
\hline$\$ 15,000-\$ 35,000 / \mathrm{yr}$ & 342 & & $124(36 \%)$ & \\
\hline$>\$ 35,000 / \mathrm{yr}$ & 276 & & & 0.0041 \\
\hline \multicolumn{5}{|l|}{ Education } \\
\hline$<$ High school & 123 & & & \\
\hline High school & 194 & & & \\
\hline$>$ High school & 465 & & 100 & 0.68 \\
\hline \multicolumn{5}{|l|}{ ADL score } \\
\hline 0 to 13 & 264 & $149(56$ & $115(44 \%)$ & \\
\hline 14 & & $370(7$ & $148(29 \%)$ & 0.0001 \\
\hline \multicolumn{5}{|l|}{ IADL score } \\
\hline 0 to 13 & & $116(50 \%)$ & $117(50 \%)$ & \\
\hline 14 & & & $146(27 \%)$ & \\
\hline Health (self-rated) & & & & 0.0001 \\
\hline Poor & & $2(17 \%)$ & $10(83 \%)$ & \\
\hline Fair & 117 & $63(54 \%)$ & $54(46 \%)$ & \\
\hline Good & 304 & $184(61 \%)$ & $120(40 \%)$ & \\
\hline Very good & & $203(77 \%)$ & $62(23 \%)$ & \\
\hline Excellent & & $67(80 \%)$ & $17(20 \%)$ & 0.0001 \\
\hline Continu & & Mean (S.D.) & Mean (S.D.) & $P$ Value \\
\hline & & $82.7(5.3)$ & $81.6(7.2)$ & 0.048 \\
\hline & & $29.0(5.3)$ & $28.1(5.9)$ & 0.035 \\
\hline & & Alive & Dead & \\
\hline & $\mathrm{N}$ & Mean (S.D.) & Mean (S.D.) & $P$ Value \\
\hline SF-36 General Health & 775 & $68.2(17.5)$ & $58.0(19.6)$ & $<0.0001$ \\
\hline Health (0 to 100$)$ & 733 & $79.1(15.5)$ & $70.4(18.1)$ & $<0.0001$ \\
\hline QWB-SA (0 to 1$)$ & 775 & $0.65(0.12)$ & $0.60(0.13)$ & $<0.0001$ \\
\hline \multicolumn{5}{|l|}{ CPCI } \\
\hline Comprehensive (0 to 6 ) & 778 & $5.0(0.6)$ & $5.0(0.7)$ & 0.72 \\
\hline Acc. Knowledge (0 to 6$)$ & 780 & $4.8(0.9)$ & $4.7(0.9)$ & 0.69 \\
\hline Communication (0 to 6 ) & 772 & $4.8(0.8)$ & $4.7(0.8)$ & 0.18 \\
\hline Pref. Reg. Doctor (0 to 6) & 782 & $5.0(0.7)$ & $5.1(0.7)$ & 0.17 \\
\hline Coordination (0 to 6$)$ & 780 & $4.3(0.9)$ & $4.4(0.9)$ & 0.005 \\
\hline
\end{tabular}


Table 1. Continued

\begin{tabular}{lcccc}
\hline Characteristics & All & Alive & Dead & $P$ Value \\
\hline Advocacy (0 to 6) & 780 & $5.0(0.6)$ & $5.1(0.6)$ & 0.10 \\
Family (0 to 6) & 725 & $4.2(1.4)$ & $4.1(1.4)$ & 0.18 \\
Community (0 to 6) & 774 & $4.4(1.3)$ & $4.4(1.4)$ & $0.57(0.3)$ \\
UPC (0 to 1) & 779 & $0.62(0.3)$ & $38.1(5.4)$ & 0.92 \\
Total CPCI (0 to 49) & 757 & $38.3(5.3)$ & $10.5(9.0)$ & 0.73 \\
Yrs with PCP mean (S.D.) & 775 & $10.5(8.7)$ & 0.46 \\
\hline
\end{tabular}

PCP, primary care physician; ADL, activities of daily living; IADL, instrumental activities of daily living; BMI, body mass index; QWB-SA, Quality of Well-Being Self-Administered Scale; CPCI, Components of Primary Care Index (scale 0 to 5 for subscales, 0 to 40 for total); Acc. Knowledge, accumulated knowledge; Pref. Reg. Doctor, preference for regular physician; UPC, proportion of care from PCP; Yrs with PCP, duration of current primary care PCP-participant relationship in years.

fewer than $50 \%$ of the items on the CPCI questionnaire or who could not be classified because of failure to complete the ADL or IADL scales. Patients who changed PCPs had lower total CPCI scores than those who did not (36.3 vs $38.2 ; P=$ $.007)$, but the only subscale score that was lower for those who changed PCPs was Family Orientation ( 3.5 vs $4.2 ; P=.0002)$. The final study population then included 782 individuals. Baseline characteristics of the study population are shown in Table 1.

\section{Severity of Illness Subgroups}

Table 2 shows the differences across the three "severity of illness" subgroups. Qur a priori categorization rules achieved our goal, which was to define clinically recognizable subgroups with different levels of severity of illness, HRQoL, and mortality rates. Nearly all CPCI subscale means were higher in the middle group (high utilizers). This appeared to be due primarily to an association between $\mathrm{CPCI}$ subscale scores and frequency of PCP visits $(P<$ $.0001)$.

\section{Outcomes by Physician}

Total CPCI scores by PCP ranged from 32.1 to 41.5. There was no association between average total CPCI scores by PCP and baseline QWB-SA, final QWB-SA, or mortality. In fact, the two PCPs whose patients had the highest rates of survival and whose HRQoL improved over time had average to low mean CPCI scores.

\section{Associations Between Baseline Variables and HRQoL}

There were positive associations between higher baseline QWB-SA scores and younger age, male sex, being married, having had more education, higher income, higher body mass index (BMI), bet- ter function (ADL, IADL, all SF-36 subscales), better self-rated health, no hearing loss, absence of several chronic conditions (heart disease, stroke, diabetes, and hypertension), and fewer physician and outpatient visits in the previous year. In the linear regression model including all participants, higher baseline QWB-SA was associated with younger age, lower morbidity score, higher IADL score, higher self-rated health, and fewer visits to physicians in the previous year.

Linear regression models revealed no associations between baseline QWB-SA scores and any of the other baseline variables in the disabled subgroup. In the nondisabled groups, the only predictor of higher baseline QWB-SA scores was fewer total outpatient visits in the year before enrollment. In the high utilizer subgroup, higher baseline QWB-SA scores were also associated with higher self-rated health and Emotional Health subscale scores (SF-36).

\section{Associations between CPCI scores and HRQoL over time}

After stratification into the severity of illness subgroups, and after controlling for baseline age, sex, race, income, education, BMI, marital status, general health, years with PCP, number of chronic illnesses, General Health, and number of primary care visits, neither CPCI total nor any of the CPCI subscale scores was associated with changes in QWB-SA scores over time in any of the subgroups based on hierarchical longitudinal growth curve analyses (Table 3). A higher proportion of visits with the participants' usual PCP was associated with more positive trends in QWB-SA scores in the healthiest subgroup $(P=.02)$, but these associations did not reach our specified level of statistical 
Table 2. Characteristics of "Severity of Illness" Subgroups, ADL + 1ADL $<27$ ( 0 to 28); ADL + IADL $>26$ and $>4$ PCP Visits/Year; and ADL + IADL $>26$ and $<5$ PCP Visits Per Year

\begin{tabular}{|c|c|c|c|c|}
\hline \multirow[b]{2}{*}{ Categorical Variables } & \multicolumn{4}{|c|}{ Nondisabled } \\
\hline & Disabled & High Utilizers & $\begin{array}{c}\text { Low } \\
\text { Utilizers }\end{array}$ & $P$ Value \\
\hline & 185 & 197 & 400 & \\
\hline \multicolumn{5}{|l|}{ Age } \\
\hline 65 to 74 & $11(27 \%)$ & $11(27 \%)$ & & \\
\hline 75 to 84 & $87(18 \%)$ & $121(26 \%)$ & & \\
\hline $85+$ & $87(32 \%)$ & $65(24 \%)$ & & \\
\hline Sex & & & & 0.002 \\
\hline Female & $57(17 \%)$ & $84(25 \%)$ & & \\
\hline Male & $128(29 \%)$ & $113(25 \%)$ & & \\
\hline Race & & & & 0.43 \\
\hline White & $153(23 \%)$ & & $347(52 \%)$ & \\
\hline Non-white & $32(28 \%)$ & & $53(53 \%)$ & \\
\hline Marital status & & & & 0.11 \\
\hline Married & $74(27 \%)$ & & & \\
\hline Other & $107(21 \%)$ & & $2(54 \%)$ & \\
\hline Income & & & & 0.0010 \\
\hline$<\$ 15,000$ & $50(35 \%)$ & $34(24 \%)$ & $57(40 \%)$ & \\
\hline$\$ 15,000-\$ 35,000 / \mathrm{yr}$ & $81(24 \%)$ & $90(26 \%)$ & $171(50 \%)$ & \\
\hline$>\$ 35,000 / 7 \mathrm{r}$ & & $67(24 \%)$ & $160(58 \%)$ & \\
\hline Education & & & & 0.0038 \\
\hline$<$ High school & & & $55(45 \%)$ & \\
\hline High school & & & $90(46 \%)$ & \\
\hline$>$ High school & & & $255(55 \%)$ & \\
\hline Confidant & & & & 0.10 \\
\hline Present & & $26(25 \%)$ & $46(44 \%)$ & \\
\hline Absent & $50(22 \%)$ & $170(25 \%)$ & $354(53 \%)$ & \\
\hline Health & & & & 0.0001 \\
\hline Poor & 100 & $0(0 \%)$ & $2(17 \%)$ & \\
\hline Fair & & $29(25 \%)$ & $26(22 \%)$ & \\
\hline Good & & $83(27 \%)$ & $141(46 \%)$ & \\
\hline Very good & & $67(25 \%)$ & $177(67 \%)$ & \\
\hline Excellent & & $18(21 \%)$ & $54(64 \%)$ & \\
\hline Morbidity Inc & 18) & $1.46(1.08)$ & $1.07(0.92)$ & \\
\hline $\mathrm{BMI} \rightleftharpoons$ & $30.84(6.55)$ & $28.96(5.32)$ & $28.02(4.98)$ & 0.0002 \\
\hline Rating (0 to 100 ) & $65.09(17.59)$ & $76.02(14.93)$ & $81.17(15.07)$ & $<0.0001$ \\
\hline QWB-SA (0 to 1$)$ & $0.53(0.12)$ & $0.64(0.11)$ & $0.67(0.11)$ & $<0.0001$ \\
\hline \multicolumn{5}{|l|}{ MOS SF-36 } \\
\hline General Health (0 to 100$)$ & $50.38(18.36)$ & $64.30(15.83)$ & $71.57(16.50)$ & $<0.0001$ \\
\hline Emotional Health (0 to 100$)$ & $75.32(17.56)$ & $78.30(15.92)$ & $82.30(14.55)$ & $<0.0001$ \\
\hline Years with current PCP & $10.0(9.1)$ & $11.4(8.8)$ & $10.1(8.6)$ & 0.81 \\
\hline Median & 7 & 10 & 8 & \\
\hline PCP visits* & $5.7(4.3)$ & $8.4(5.3)$ & $2.6(1.1)$ & $<0.0001$ \\
\hline Median & 5 & 6 & 3 & \\
\hline Other visits to practice* & $0.80(1.53)$ & $0.90(1.7)$ & $0.47(1.11)$ & 0.0002 \\
\hline Median & 0 & 0 & 0 & \\
\hline \multirow[t]{2}{*}{ Other health care visits* } & $5.5(7.8)$ & $4.2(4.9)$ & $2.8(4.2)$ & $<0.001$ \\
\hline & & & & Continued \\
\hline
\end{tabular}


Table 2. Continued

\begin{tabular}{|c|c|c|c|c|}
\hline \multirow[b]{2}{*}{ Categorical Variables } & \multicolumn{4}{|c|}{ Nondisabled } \\
\hline & Disabled & High Utilizers & Low & $P$ Value \\
\hline Median & 4 & 3 & 2 & \\
\hline ED visit rate* & $0.59(1.71)$ & $0.21(0.46)$ & $0.11(0.36)$ & 0.001 \\
\hline Median & 0.12 & 0 & 0 & \\
\hline Hospitalization rate Mn (S.D.) & $0.45(0.94)$ & $0.21(0.46)$ & $0.11(0.33)$ & \\
\hline Median & 0.06 & 0 & 0 & \\
\hline Deaths, n (\%) & $99(53.5)$ & $63(32.0)$ & $101(2$ & $<0.0001$ \\
\hline Survival time & $7.4(3.4)$ & $8.7(2.9)$ & & $<0.0001$ \\
\hline Comprehensiveness & $5.02(0.69)$ & $5.19(0.61)$ & & 0.1112 \\
\hline Accumulated knowledge & $4.80(0.93)$ & $5.00(0.77)$ & & 0.0002 \\
\hline Communication & $4.65(0.90)$ & $4.86(0.78)$ & & 0.28 \\
\hline Preference for regular doctor & $5.12(0.69)$ & $5.23(0.63)$ & & 0.0006 \\
\hline Coordination & $4.48(0.86)$ & $4.59(0.82)$ & $(0.9$ & $<0.0001$ \\
\hline Advocacy & $5.10(0.67)$ & & $4.98(0.59)$ & 0.0031 \\
\hline Considers family context & $4.27(1.39)$ & & $4.01(1.37)$ & 0.0141 \\
\hline Community Cont. & $4.52(1.30)$ & & $4.34(1$ & 0.3545 \\
\hline UPC & $0.55(0.27)$ & & 0 & 0.002 \\
\hline Total CPCI & $38.5(5.7)$ & & & 0.0018 \\
\hline
\end{tabular}

ADL, activities of daily living; IADL, instrumental activities of daily living; BMI, body mass index; QWB-SA, Quality of Well-Being Self-Administered Scale; MOS SF-36, 36-item Medical Outcome Study Short-Form Health Survey; PCP, primary care physician; ED, emergency department; UPC, proportion of care from PCP; CPCI, Components of Primary Care Index.

significance. Analyses using transformed CPCI scores were not significantly different from those using untransformed scores.

\section{Associations Between Baseline Variables and Mortality}

Table 1 displays the independent associations between baseline population characteristics and mortality. Two hundred sixty-three (34\%) participants had died as of March 31, 2010. The data set then, with respect to mortality, includes up to a maximum of 10 calendar years and 6460 person-years of follow-up. Survival was associated with younger age, higher income, better function, higher BMI, better self-rated health, and higher QWB-SA scores at baseline (Table 1). Logistic regression modeling demonstrated no associations between survival and any explanatory variables within the disabled subgroup. Predictors of survival in the high using group included female sex and higher General Health at baseline. Within the healthiest subgroup, survival was associated with younger age, income above the lowest category, and fewer outpatient visits in the year before enrollment.

\section{Associations Between CPCI Scores and Mortality}

After controlling for baseline age, sex, race, income, education, BMI, marital status, general health, years with PCP, morbidity score, and number of visits to the PCP in the year before enrollment, Cox proportionate hazards models identified an association between higher CPCI Coordination scores and earlier mortality in the nondisabled, high-using subgroup $(P=.01)$ (Table 4). Possible associations between higher scores on Coordination and Advocacy and reduced survival in the disabled subgroup did not reach statistical significance ( $P=.03$ and $P=.02$, respectively). Analyses using transformed CPCI scores were not significantly different from those using untransformed scores.

\section{Discussion}

The concept of evidence-based medicine is predicated on the assumption that the goal of health care is to improve outcomes. Two of the more important health outcomes are enhanced quality of life and prolongation of survival. To the extent that effectiveness is defined in terms of those outcomes, our results suggest that older patients' ratings of their primary care on the CPCI questionnaire are not good measures of effectiveness of care. If this is 
Table 3. Longitudinal Growth Curve Model for HRQoL (QWB-SA) Within Severity of Illness Subgroups

a. Disabled

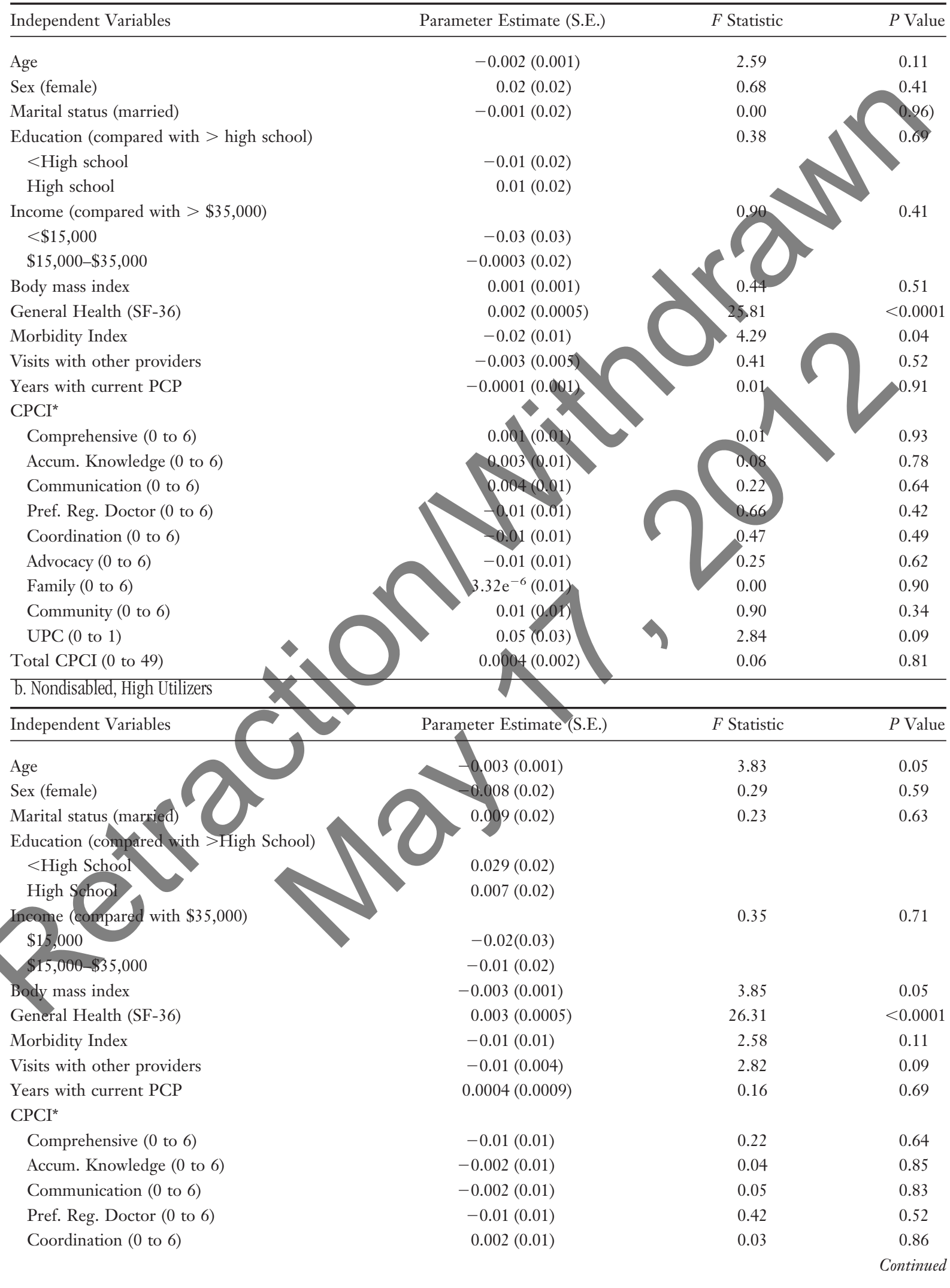


Table 3. Continued

\begin{tabular}{|c|c|c|c|}
\hline Independent Variables & Parameter Estimate (S.E.) & $F$ Statistic & $P$ Value \\
\hline $\operatorname{Advocacy}(0$ to 6$)$ & $-0.01(0.01)$ & 0.99 & 0.32 \\
\hline Family (0 to 6 ) & $0.01(0.01)$ & 4.30 & 0.04 \\
\hline Community (0 to 6$)$ & $-0.01(0.01)$ & 1.57 & 0.21 \\
\hline UPC (0 to 1$)$ & $0.01(0.04)$ & 0.05 & 0.83 \\
\hline Total CPCI (0 to 49$)$ & $-0.0005(0.002)$ & 0.09 & 0.77 \\
\hline \multicolumn{4}{|l|}{ c. Nondisabled, Low Utilizers } \\
\hline Independent Variables & Parameter Estimate (S.E.) & & $P$ Value \\
\hline Age & $-0.003(0.0009)$ & & 0.001 \\
\hline Sex (female) & $0.02(0.01)$ & & 0.10 \\
\hline Marital status (married) & $0.02(0.01)$ & & 0.13 \\
\hline Education (compared with $>$ & & & 0.24 \\
\hline$<$ High School & $0.020(0.02)$ & & \\
\hline High School & $0.02(0.01)$ & & \\
\hline \multirow{3}{*}{\multicolumn{4}{|c|}{$\begin{array}{l}\text { Income (compared with } \$ 35,000 \text { ) } \\
\quad \$ 15,000 \\
\quad \$ 15,000-\$ 35,000\end{array}$}} \\
\hline & & & \\
\hline & & & \\
\hline Body mass index & & & 0.10 \\
\hline General Health (SF-36) & & & $<0.0001$ \\
\hline Morbidity Index & & & 0.009 \\
\hline Visits with other providers & $0.002(0.003)$ & 0.68 & 0.41 \\
\hline Years with current PCP & $0.001(0.001)$ & 2.09 & 0.15 \\
\hline \multicolumn{4}{|l|}{$\mathrm{CPCI}^{*}$} \\
\hline Comprehensive ( 0 to 6 ) & & 0.94 & 0.33 \\
\hline Accum. Knowledge (0 to 6$)$ & $-0.003(0.01)$ & 0.29 & 0.59 \\
\hline Communication (0 to 6 ) & $0.01(0.01)$ & 1.52 & 0.22 \\
\hline Pref. Reg. Doctor (0 to 6) & $-0.001(0.01)$ & 0.01 & 0.94 \\
\hline Coordination (0 to 6 ) & $0.01(0,01)$ & 4.04 & 0.05 \\
\hline Advocacy (0 to 6$)$ & $-0.002(0.01)$ & 0.04 & 0.84 \\
\hline Family (0 to 6 ) & $003(0.004)$ & 0.67 & 0.41 \\
\hline Community (0 to 6$)$ & & 0.23 & 0.63 \\
\hline UPC (0 to 1$)$ & & 5.19 & 0.02 \\
\hline Total CPCI $(0$ to & $0005(0.001)$ & 0.25 & 0.62 \\
\hline
\end{tabular}

${ }^{*}$ CPCI total and subscale scores were entered separately (10 separate models are represented. CPCI scores were not transformed. HRQoL, health-related quality of life; QWB-SA, Quality of Well-Being Self-administered Scale; PCP, primary care physician; CPCI, Components of Primary Care Index; UPC, proportion of care from PCP.

true, then patient satisfaction scores should probably not be relied on as measures of clinical effectiveness, though they might still be regarded as subjective indicators of other aspects of quality. Of course, we can say nothing about the relationship between CPCI scores and other important outcomes such as enhanced personal growth and development, enhanced family stability, or a more comfortable dying process.

These results should not be too surprising. Patients often, very naturally, value immediate comfort more than future health. Primary care physicians in the private sector are under pressure to please patients because they are, after all, customers. The subject matter is complex, and so physician personality traits and confidence can be easily mistaken for clinical competence.

Studies of student ratings of teachers' performance are illuminating. Students have been found to be accurate judges of certain aspects of teaching including "how clear, interesting, respectful, and fair" a teacher is, as well as how well the teacher was able to motivate them to learn the material. However, students are not able to provide reliable information on the quality of the course objectives, the content of the course, or the course assign- 
Table 4. Cox proportionate Hazards Models for Each Severity of Illness Subgroup

a. Disabled

\begin{tabular}{|c|c|c|c|}
\hline Independent Variables & Hazard Ratio (C.I.95\%)) & $\chi^{2}$ Statistic & $P$ Value \\
\hline Age & $0.94(0.90,0.98)$ & 8.01 & 0.005 \\
\hline Sex (female) & $0.57(0.32,1.00)$ & 3.86 & 0.05 \\
\hline Marital status (married) & $0.55(0.32,0.94)$ & 4.70 & 3 \\
\hline Education & $0.93(0.69,1.26)$ & 0.22 & 0.64 \\
\hline Income & $0.90(0.62,1.31)$ & 0.30 & 0.58 \\
\hline Body mass index & $0.96(0.94,0.99)$ & 10.00 & 0.002 \\
\hline General Health (SF-36) & $0.99(0.98,1.00)$ & 2.23 & 0.14 \\
\hline Morbidity Index & $0.89(0.73,1.08)$ & 1.3 & 0.25 \\
\hline Visits with other providers & $0.98(0.84,1.14)$ & & 0.80 \\
\hline Years with current PCP & $0.99(0.97,1.02)$ & & 0.62 \\
\hline \multicolumn{4}{|l|}{$\mathrm{CPCI}^{*}$} \\
\hline Comprehensive (0 to 6 ) & $1.32(0.94,1.86)$ & & 0.11 \\
\hline Acc. Knowledge (0 to 6 ) & $1.08(0.81,1.43)$ & 0.2 & 0.59 \\
\hline Communication (0 to 6 ) & $1.01(0.78,1.30)$ & 0.001 & 0.97 \\
\hline Pref. Reg. Doctor (0 to 6) & $1.12(0.83,1.53)$ & 0.54 & 0.46 \\
\hline Coordination (0 to 6 ) & $1.39(1.02,1.89)$ & & 0.03 \\
\hline Advocacy (0 to 6) & 1 & 5.1 & 0.02 \\
\hline Family (0 to 6$)$ & 1.04 & 0. & 0.34 \\
\hline Community (0 to 6$)$ & & & 0.23 \\
\hline UPC (0 to 1$)$ & (3) & 2.36 & 0.12 \\
\hline Total CPCI (0 to 49$)$ & 1.10) & 2.8 & 0.09 \\
\hline \multicolumn{4}{|l|}{ b. Nondisabled, High Utilizers } \\
\hline Independent Variables & & $x^{2}$ Statistic & $P$ Value \\
\hline Age & & 3.06 & 0.08 \\
\hline Sex (female) & $0.0 \%, 0.30$ & 26.06 & $<0.0001$ \\
\hline Marital status (married) & $0.29(0.14,0.59)$ & 11.82 & 0.0006 \\
\hline Education & $1.02(0.66,1.57)$ & 0.004 & 0.95 \\
\hline Income & $0.85(0.51,1.41)$ & 0.40 & 0.53 \\
\hline Body mass index & $0.93(0.88,0.98)$ & 7.04 & 0.008 \\
\hline General Health & 998 & 0.74 & 0.39 \\
\hline Morbidity I & 89) & 7.47 & 0.006 \\
\hline Visits with other providers & , 1.29) & 5.93 & 0.01 \\
\hline ent PEP & $1.02(0.99,1.05)$ & 1.52 & 0.22 \\
\hline Comprehensive (0 to 6 ) & $1.11(0.73,1.69)$ & 0.24 & 0.63 \\
\hline Acc. Knowledge (0 to 6) & $1.02(0.68,1.52)$ & 0.008 & 0.93 \\
\hline Communication (0 to 6 ) & $0.94(0.65,1.38)$ & 0.09 & 0.76 \\
\hline Pref. Reg. Doctor (0 to 6) & $1.51(0.99,2.30)$ & 3.65 & 0.06 \\
\hline Coordination (0 to 6 ) & $1.59(1.11,2.26)$ & 6.50 & 0.01 \\
\hline Advocacy (0 to 6$)$ & $1.93(1.17,3.20)$ & 6.60 & 0.01 \\
\hline Family (0 to 6 ) & $1.07(0.86,1.34)$ & 0.39 & 0.53 \\
\hline Community (0 to 6$)$ & $1.10(0.87,1.38)$ & 0.60 & 0.44 \\
\hline UPC (0 to 1$)$ & $0.69(0.19,2.59)$ & 0.30 & 0.58 \\
\hline Total CPCI (0 to 49$)$ & $1.05(0.99,1.11)$ & 2.44 & 0.12 \\
\hline
\end{tabular}


Table 4. Continued

c. Nondisabled, Low Utilizers

\begin{tabular}{|c|c|c|c|}
\hline Independent Variables & Hazard Ratio (C.I.95\%)) & $\chi^{2}$ Statistic & $P$ Value \\
\hline Age & $0.93(0.89,0.97)$ & 11.13 & 0.0008 \\
\hline Sex (female) & $0.66(0.41,1.06)$ & 2.91 & 0.09 \\
\hline Marital status (married) & $0.46(0.27,0.78)$ & 8.25 & 0.004 \\
\hline Education & $1.43(1.02,2.01)$ & 4.36 & 0.04 \\
\hline Income & $0.71(0.49,1.04)$ & 3.15 & 0.08 \\
\hline Body mass index & $0.97(0.93,1.02)$ & 1.18 & 0.28 \\
\hline General Health (SF-36) & $0.98(0.97,0.99)$ & 8.55 & 0.004 \\
\hline Morbidity Index & $1.11(0.89,1.39)$ & 0.85 & 0.36 \\
\hline Visits with other providers & $1.02(0.92,1.14)$ & & 0.72 \\
\hline Years with current PCP & $1.00(0.97,1.03)$ & & 0.79 \\
\hline \multicolumn{4}{|l|}{$\mathrm{CPCI}^{*}$} \\
\hline Comprehensive (0 to 6 ) & $0.91(0.64,1.29)$ & & 0.60 \\
\hline Acc. Knowledge (0 to 6 ) & $0.88(0.68,1.14)$ & & 0.33 \\
\hline Communication (0 to 6 ) & $0.86(0.66,1.13)$ & 1.19 & 0.28 \\
\hline Pref. Reg. Doctor (0 to 6) & $1.24(0.90,1.71)$ & 1.74 & 0.19 \\
\hline Coordination (0 to 6$)$ & $1.002(0.7$ & & 0.99 \\
\hline Advocacy (0 to 6$)$ & $1.01(0$ & & 0.95 \\
\hline Family (0 to 6 ) & 0.9 & & 0.80 \\
\hline Community (0 to 6$)$ & & & 0.87 \\
\hline $\mathrm{UPC}(0$ to 1$)$ & 0.88 & 0.10 & 0.76 \\
\hline Total CPCI (0 to 49$)$ & $0.99(0$. & & 0.78 \\
\hline
\end{tabular}

\section{$>$}

ments. ${ }^{13}$ Translating this to the clinical arena, patients are the best judges of their experience of care but can probably not be relied on to accurately assess the appropriateness of clinical evaluations and recommendations.

This study was limited in several ways. Patient satisfaction surveys are notorious for both ceiling (leftward skew) and halo (generally positive feelings toward PCPs raise all subscale scores) effects. We transformed the scores to address the skew, we looked at total CPCI scores as well as the subscales, and we controlled for duration of the patient-PCP relationship, but those were only partial remedies.

Severity of illness and its reflection in patients' need for and experience with certain primary care functions (eg, coordination) are difficult to measure. Even though we used a two-step process, first stratifying and then controlling for number of chronic conditions, similar but not identical to commonly used methods, ${ }^{14,15}$ and the General Health subscale of the SF-36, we are not confident that we removed all of the confounding caused by this factor. Weiner, Starfield, and colleagues have described a more comprehensive measure, ${ }^{16}$ but, unfortunately, we did not have all of the data required for use of this measure.

There was a high dropout rate over the 4 years of the study, resulting in a large number of missing values for HRQoL beyond baseline. This reduced our chance to find associations. The growth curve analysis used all the data that were available, however. The QWB-SA is fairly sensitive to small changes, but perhaps not sensitive enough to detect weak associations between CPCI scores and changes in HRQoL over short periods of time. We believe that we captured all or very nearly all deaths, so those calculations should not have been affected.

We chose to exclude individuals who changed doctors during the first 4 years of the study, reasoning that those patients would be less likely to have time to benefit from the care they were evaluating. A potential disadvantage of this decision is that poor ratings of the functions of primary care might prompt patients to change physicians, further truncating the spread of scores that already seem to 
be skewed toward the positive rating. In fact, in a previous analysis of OKLAHOMA Studies data, the accumulated knowledge, communication, and family orientation subscale scores did predict change in PCP. ${ }^{17}$

This is the first study to attempt to determine whether the CPCI can discriminate between better or worse primary care. Only a few other published studies have reported the results of analyses of associations between patient assessments of the quality of their primary care and outcomes. Safran, using an instrument similar to the CPCI, ${ }^{2}$ found, in a cross-sectional analysis of employed adults, that patient perceptions of their physicians' whole-person knowledge about them was associated with adherence to physician recommendations regarding behavioral risk factors. ${ }^{18}$ There were also small but statistically significant associations between trust, communication, thoroughness of exams, physician's knowledge of the patient, and integration of care and patient-reported improvements in health status over the previous 4 years. In this study, the researchers used the physical and mental health subscale scores from the Medical Outcomes Study's SF-12, chronic medical diagnoses from a list of 21 conditions, and behavioral risk factors.

In a separate study using the same instrument, however, there was no consistent association between patients' assessment of primary care quality and clinician or practice performance on the HEDIS quality of care measures. The authors concluded that "clinical quality and patient experience are distinct but related domains that require separate measures and improvement initiatives." 19

Kerse and colleagues studied adults being cared for in primary care practices in New Zealand. Patients completed a waiting room survey about attributes of their relationship with their PCP before a visit. They were then interviewed by phone 4 days later and queried about adherence to medications prescribed at the index visit. They found that PCP-patient concordance was associated with subsequent adherence. ${ }^{20}$ Most recently, Bertakis and Azari found that patientcentered primary care encounters were associated with lower costs of care over the subsequent year. However, patient satisfaction was not associated with more objectively rated patient-centered care, based on scored videotaped encounters. ${ }^{21}$

The strengths of our study include its prospective cohort design and our two-step process of controlling for severity of illness (stratification, then statistical adjustment within the strata). For the survival analyses, our average period of follow-up was reasonably long, and a substantial proportion (34\%) had died. Although the average duration of follow-up for quality of life was relatively short, the participants were all over the age of 65 , making short-term changes in quality of life more likely.

\section{Conclusions}

This study casts doubt on the ability of older patients to accurately judge the effectiveness of their primary care. It does not, however, mean that patient satisfaction is worthless. Obviously, we would prefer that patients live longer and better and feel positively about the care they are receiving.

\section{References}

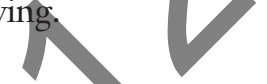

Flocke SA. Measuring attributes of primary care: development of a new instrument. J Fam Pract 1997; 45:64-74.

Safran DG, Kosinski M, Tarlow AR, et al. The primary care assessment survey: tests of data quality and measurement performance. Med Care 1998;36: $728-39$.

3. Starfield B, Shi L, Macinko J. Contribution of primary care to health systems and health. Millbank Quart 2005;83:457-502.

4. Stange KC, Zayzanski SJ, Jaen CR, et al. Illuminating the "black box": a description of 4454 patient visits to 138 family physicians. J Fam Pract 1998;46: $377-89$.

5. Institute of Medicine. Defining primary care: an interim report. Washington, D.C.: National Academy Press; 1994.

6. Shi L. Primary care, specialty care, and life chances. Int J Health Services 1994;24:431-58.

7. Farmer FL, Stokes CS, Fiser RH, Papini DP. Poverty, primary care, and age-specific mortality. J Rural Health 1991;7:153-69.

8. Ferrer RL, Hambridge SJ, Maly RC. The essential role of generalists in health care systems. Ann Intern Med 2005;142:691-9.

9. Ranganathan M, Hibbard J, Rodday AMC, et al. Motivating public use of physician-level performance data: an experiment on the effects of message and mode. Med Care 2009;66: $68-81$.

10. Werner RM, Asch DA. The unintended consequences of publicly reporting quality information. JAMA 2005;293:1239-44.

11. Mold JW, Fryer G, Roberts M. When do older patients change primary care physicians? J Am Board Fam 2004;17:453-60. 
12. Mold JW, Vesely SK, Keyl BA, et al. The prevalence, predictors, and consequences of peripheral sensory neuropathy in older patients. J Am Board Fam Pract 2004;17:309-18.

13. Felder RM, Brent R. How to evaluate teaching. Clin Eng Educ 2004;38:200-2.

14. Charlson ME, Pompei P, Ales KL, et al. A new method of classifying prognostic comorbidity in longitudinal studies: development and validation. J Chron Dis 1987;40:373-83.

15. Zhu H, Hill MD. Stroke: the Elixhauser Index for comorbidity adjustment of in-hospital case fatality. Neurology 2008;71:283-7.

16. Weiner JP, Starfield BH, Steinwachs DM, Mumford LM. Development and application of a populationoriented measure of ambulatory care case-mix. Med Care 1991;29:452-72.
17. Mold JW, Fryer GE, Roberts M. When do older patients change primary care physicians? JABFM 2004;17:453-60.

18. Safran DG, Taira DA, Rogers WH, et al. Linking primary care performance to outcomes of care. J Fam Pract 1998;47:213-20.

19. Sequist TD, Schneider EC, Anastario M, et al. Quality monitoring of physicians: linking patients' experiences of care to clinical quality and outcomes. J Gen Intern Med 2008;23:1784-90.

20. Kerse N, et al. Physician-patient relationship and medication compliance: a primary care investigation. Ann Fam Med 2004;2:455-61.

21. Bertakis KD, Azari R. Determinants and outcomes of patient-centered care. Patient Educ Counsel 2010. In press.

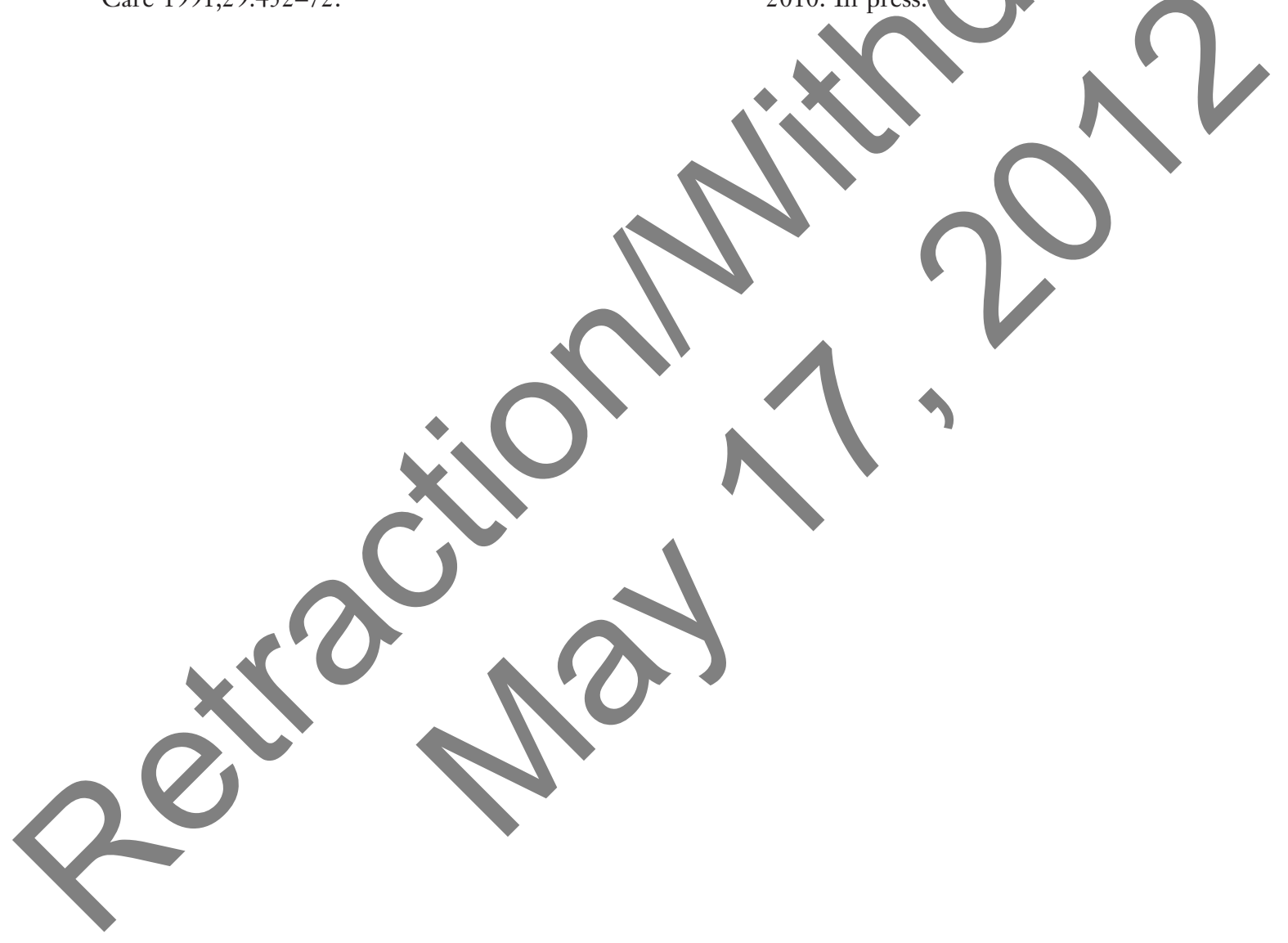

